\title{
Investigation on Yield Behavior of 7075-T6 Aluminum Alloy at Elevated Temperatures
}

\author{
Jianping Lin' ${ }^{1}$ Xingyu Bao ${ }^{1}$, Yong Hou' ${ }^{1}$ Junying Min ${ }^{*} \mathbb{E}$, Xinlei $\mathrm{Qu}^{2}$, Zhimin Tao ${ }^{2}$ and Jiajie Chen ${ }^{3}$
}

\begin{abstract}
Aluminum alloys have drawn considerable attention in the area of automotive lightweight. High strength aluminum alloys are usually deformed at elevated temperatures due to their poor formability at room temperature. In this work, the yield behavior of 7075 aluminum alloy in T6 temper (AA7075-T6) within the temperature ranging from $25^{\circ} \mathrm{C}$ to $230^{\circ} \mathrm{C}$ was investigated. Uniaxial and biaxial tensile tests with the aid of induction heating system were performed to determine the stress vs. strain curves and the yield loci of AA7075-T6 at elevated temperatures, respectively. Von Mises, Hill48 and Yld2000-2d yield criteria were applied to predicting yield loci which were compared with experimentally measured yield loci of the AA7075-T6. Results show that yield stress corresponding to the same equivalent plastic strain decreases with increasing temperature within the investigated temperature range and the shape of yield loci evolves nearly negligibly. The experimental yield locus expands with an increase of equivalent plastic strain at the same temperature and the work hardening rate of AA7075-T6 exhibits obvious stress-state-dependency. The nonquadratic Yld2000-2d yield criterion describes the yield surfaces of AA7075-T6 more accurately than the quadratic von Mises and Hill48 yield criteria, and an exponent of 14 in the Yld2000-2d yield function gives the optimal predictions for the AA7075-T6 at all investigated temperatures.
\end{abstract}

Keywords: Aluminum alloy, Yield behavior, Biaxial tensile test, Warm condition

\section{Introduction}

Lightweight materials, e.g., advanced high strength steels and aluminum alloys, have been identified as a key priority for improving fuel efficiency of automotive [1,2]. $7 \mathrm{xxx}$-series aluminum alloys ( $\mathrm{AlZnMgCu}$ ) offer a potential to replace a portion of high strength steels [3-5]; however, formability of AA7xxx at ambient temperatures is limited. Warm forming technology is a promising approach to improve the formability of peak-aged 7075 aluminum alloys (AA7075-T6) [6-9], where the AA7075T6 blank is heated to target temperatures followed by warm forming with heated or cold dies. The formability of aluminum alloys under warm conditions can be evaluated by forming limit curves (FLCs) $[10,11]$. Sotirov et al. [12] obtained temperature-dependent forming limits of

\footnotetext{
*Correspondence: junying.min@tongji.edu.cn

${ }^{1}$ School of Mechanical Engineering, Tongji University, Shanghai 201804, China

Full list of author information is available at the end of the article
}

EN AW-7075-T6 using the Nakazima tests and found that the major strain of FLC raised from 0.15 to 0.3 at plane strain condition as the temperature increased from room temperature to $230{ }^{\circ} \mathrm{C}$. Grohmann et al. [13] compared the formability of AA7075-T6 at various temperatures with a typical automotive aluminum alloy AA6016 in T4 temper. It is concluded that at $170{ }^{\circ} \mathrm{C}$, the FLC of AA7075-T6 is similar to that of AA6016-T4 at room temperature.

To reduce the cost, finite element analysis has become an obligatory step to simulate the deformation process of sheet metals. The accuracy of numerical simulation is dependent on the constitutive model which describes the plastic deformation behavior of sheet metals. Studies have been carried out on the influence of constitutive models on the prediction accuracy of finite element analysis (FEA) for the sheet metal forming processes. Significant conclusion was drawn by Hou et al. [14] that usage of the Yoshida-Uemori kinematic hardening model [15] increases the accuracy of springback prediction for 
the U-shaped specimens of a $980 \mathrm{MPa}$ grade multiphase steel. For materials that exhibit little Bauschinger effect but pronounced texture anisotropy (e.g., AA6022-T4), the use of a yield criterion that accounts for anisotropy, e.g., Yld2000-2d, is more important for improving the accuracy of springback prediction [16]. Pilthammar et al. [17] found that the most reliable prediction of strains and forces in the simulations of Nakajima testing can be achieved by the $\mathrm{BBC} 05$ yield criterion with a non-integer exponent, demonstrating the need of yield criterion with high flexibility. In addition, there are some investigations on the yield behavior of sheet metals at elevated temperatures. Based on the results from uniaxial tensile test results, Zhou et al. [18] calculated the theoretical yield loci from the von Mises, Hill48 and Barlat89 yield criterion of AA7075-T6 at five temperatures $(50,100$, 150,200 and $250{ }^{\circ} \mathrm{C}$ ). Sheet metals are usually subjected to multiple deformation paths during forming processes, and the multiaxial formability of sheets cannot be merely investigated through the uniaxial tests. Therefore, it is of importance to investigate the mechanical properties of sheet metals under multiaxial loading conditions, e.g., biaxial tension conditions. To date, methods for biaxial tensile testing at elevated temperatures have been used in some literatures. Terriault et al. [19] conducted the equal-biaxial tensile tests and obtained the experimental yield surface of a Ti-Ni alloy using a designed pantograph and a conventional tensile testing machine. Hamasaki et al. [20] equipped the biaxial testing machine with a thermostatic bath system, and investigated the influence of temperature on the yield surface of AA5182-O. However, there are few works focused on the yield behavior of AA7075-T6 under biaxial loading condition at warm temperatures, and the applicability of various constitutive models requires further investigation.

In this paper, the deformation behavior of AA7075-T6 within the temperature range from $25{ }^{\circ} \mathrm{C}$ to $230{ }^{\circ} \mathrm{C}$ was studied through uniaxial and biaxial tensile testing with the aid of induction heating system and digital image correlation techniques. Theoretical yield loci calculated by the von Mises, Hill48 and Yld2000-2d yield criteria were compared with experimental ones at various temperatures. In addition, the influence of the exponent in

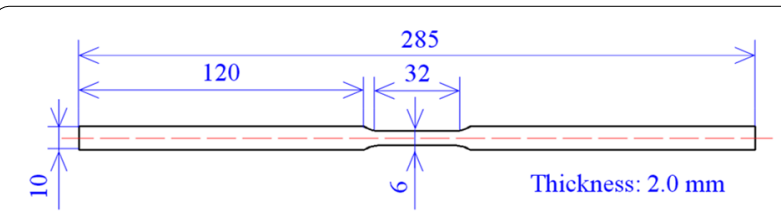

Figure 1 Dimensions of modified specimen in uniaxial tensile testing $(\mathrm{mm})$ the Yld2000-2d criterion on yield loci was investigated to improve the prediction accuracy.

\section{Experimental Details}

\subsection{Uniaxial Tensile Tests at Elevated Temperatures}

The material investigated in this work is a commercial peak aged (T6 tempered) aluminum alloy sheet, AA7075T6, with a thickness of $2.0 \mathrm{~mm}$. Uniaxial tensile specimens were modified following the ASTM Standard E8/ E8M [21] and were cut by wire electro discharge machining (WEDM) at $0^{\circ}$ (rolling direction, RD), $45^{\circ}$ (diagonal direction, DD) and $90^{\circ}$ (transverse direction, TD) to the rolling direction. In order to reduce the heat transfer from heated specimens to the hydraulic grips of the testing machine, the length of the gripper ends in specimen was extended, as shown in Figure 1. Uniaxial tensile tests were performed on the universal testing machine MTS E45.105 with the aid of induction heating at four temperatures, namely $25,130,180$ and $230{ }^{\circ} \mathrm{C}$, at a nominal strain rate of $0.001 / \mathrm{s}$. The variations of tensile rates are detailed in Table 1. Digital image correlation (DIC) techniques were used to measure strains during the tests. To prepare the speckle pattern for DIC measurements, the following standard procedure was applied. The specimen surface was cleaned with alcohol, and a layer of white paint was sprayed onto the cleaned surface and then black paint dots with sizes of $\sim 0.3 \mathrm{~mm}$ were applied onto the dried white paint layer. The DIC system was set on one side of specimen, and the induction heating coil and infrared thermal imager were set on the other side, as illustrated in Figure 2. A graphite paint layer was applied

\begin{tabular}{lccccc}
$\begin{array}{l}\text { Table } \mathbf{1} \text { Tensile } \\
\text { temperatures }\end{array}$ & rates & of & specimens & at & different \\
\hline Temp. $\left({ }^{\circ} \mathrm{C}\right)$ & $\mathbf{2 5}$ & $\mathbf{1 3 0}$ & $\mathbf{1 8 0}$ & $\mathbf{2 3 0}$ \\
\hline Tensile rate $(\mathrm{mm} / \mathrm{min})$ & 3 & 1 & 1 & 0.4 \\
\hline
\end{tabular}

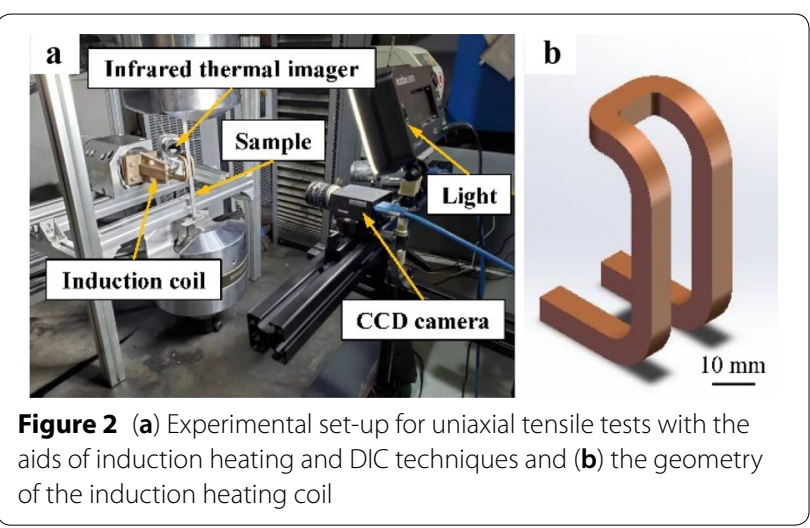


to the measured area of specimen and the infrared thermal imager provided real-time monitoring and closedloop control of the temperatures of heated specimens. The temperature of the hot spot in the measured area was used as the feedback temperature in the induction heating system. Figure 3 presents the temperature contours of a modified specimen at $230^{\circ} \mathrm{C}$. It is clear that the temperature decreases from the central area of the gage section to the gripper ends, and a uniform temperature distribution section with an approximate length of $8 \mathrm{~mm}$ was noted as depicted by the dashed square in Figure 3, where the temperature difference was controlled within $5{ }^{\circ} \mathrm{C}$ below the testing temperature. The specimens were heated to the testing temperatures followed by a holding time of 2 min to ensure a homogeneous temperature distribution on specimens, and then the specimens were pulled until localized necking or fracture happened. It should be noted that the strain data from DIC calculation within the dashed square in Figure 3 were used in the post-processing with the Vic-3D software to acquire stress vs. strain curves.

\subsection{Biaxial Tensile Tests at Elevated Temperatures}

To obtain the yield loci of AA7075-T6 at elevated temperatures, biaxial tensile tests of cruciform specimens at $25,130,180$ and $230{ }^{\circ} \mathrm{C}$ were carried out on the testing machine MTS BIA5105 equipped with an induction heating system. The dimensions of cruciform specimen are illustrated in Figure 4, where the central gage section was designed following Hanabusa et al. [22] and ISO 16842 [23]. Specimens were cut by laser, and the same operation was implemented for strain measurements using DIC techniques. The horizontal and vertical

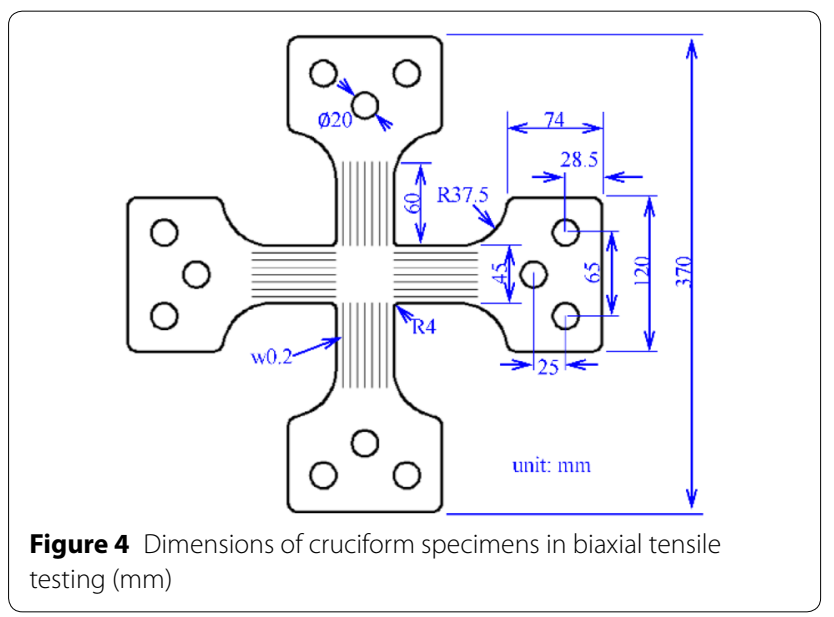

directions were defined as the $x$ and $y$-axes, respectively. The RD of specimens was along $x$-axis, and the force ratios $\left(F_{x}: F_{y}\right)$ were set to $1: 2,1: 1$, and 2:1. The DIC system was set up in front of the tested specimen, and the induction heating coil was placed $10 \mathrm{~mm}$ from the specimen on the other side, as shown in Figure 5. In order to ensure the feasibility of applying induction heating to biaxial tensile testing, the temperature contours of a cruciform specimen were measured by an infrared camera at $230{ }^{\circ} \mathrm{C}$ in Figure 6(a). A graphite paint layer was applied to the measured area of specimen. It can be found that the temperature decreased from the central area of the specimen to the surrounding arms gradually, while the temperature contours in the central square gage area ( 45 $\mathrm{mm}$ by $45 \mathrm{~mm}$ ) was relatively uniform. The temperature

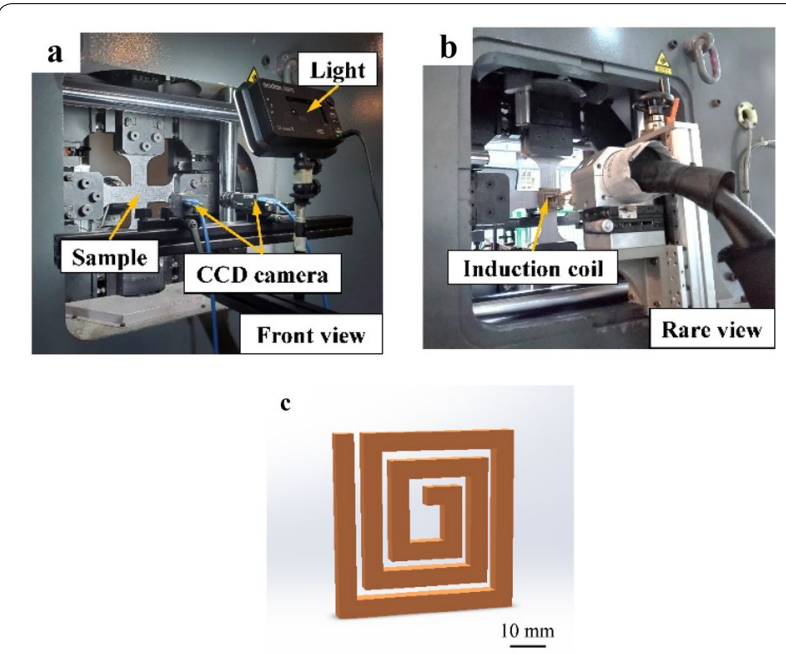

Figure 5 (a) The front view and (b) the rare view of experimental set-up for biaxial tensile tests with the aids of induction heating and DIC techniques, and (c) the geometry of the induction heating coil
Figure 3 Temperature contours of an induction-heated specimen in uniaxial tensile testing at $230^{\circ} \mathrm{C}$

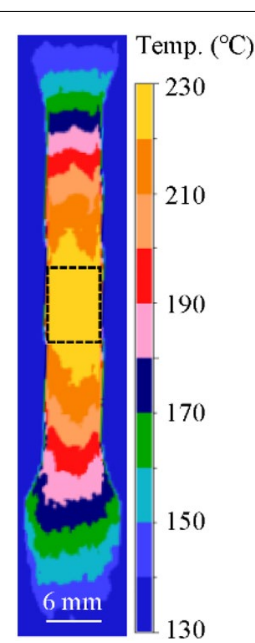



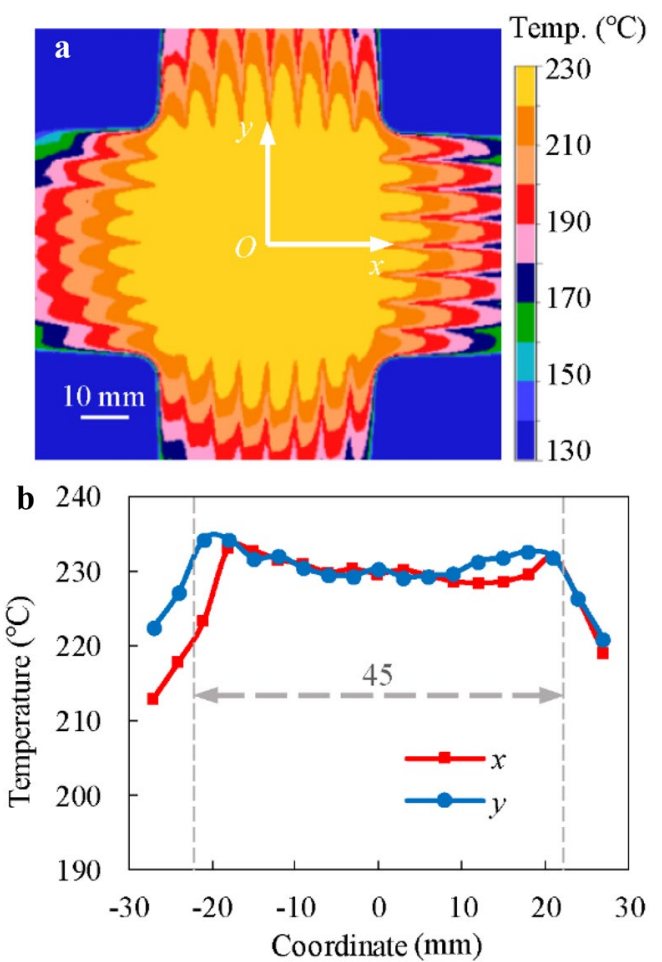

Figure 6 (a) Temperature contours of an induction-heated cruciform specimen and (b) temperature profiles along $x$-axis and $y$-axis

profiles extracted along the $x$-axis and $y$-axis are presented in Figure 6(b), where the origin of the coordinate system located in the cruciform center. Within the range of $45 \mathrm{~mm}$ along the $x$-axis and the $y$-axis, the maximum temperature was $234{ }^{\circ} \mathrm{C}$ and the lowest temperature was $222{ }^{\circ} \mathrm{C}$. Hence, the temperature fluctuation is smaller than $\pm 8{ }^{\circ} \mathrm{C}$. During the tensile testing, a thermocouple was taped to the center of the specimen using a high temperature adhesive, and the temperature at this center was monitored and used in the feedback control of the induction heating system. The heating rate was set to $\sim 150{ }^{\circ} \mathrm{C} /$ min.

The biaxial true strain components were extracted and averaged over the gage area ( $45 \mathrm{~mm}$ by $45 \mathrm{~mm}$ ) of cruciforms in the DIC software. True stress components and plastic strain components of the deformed gage regions were calculated based upon the Hooke's law and the law of volume constancy in plastic deformation. The detailed processing of stress vs. strain data in the biaxial tensile testing refers to Min et al. [24].

\section{Results and Discussion}

\subsection{Flow Curves}

Figure 7 shows the true stress $(\sigma)$ vs. equivalent plastic strain $\left(\bar{\varepsilon}_{\mathrm{p}}\right)$ curves obtained from uniaxial tensile tests
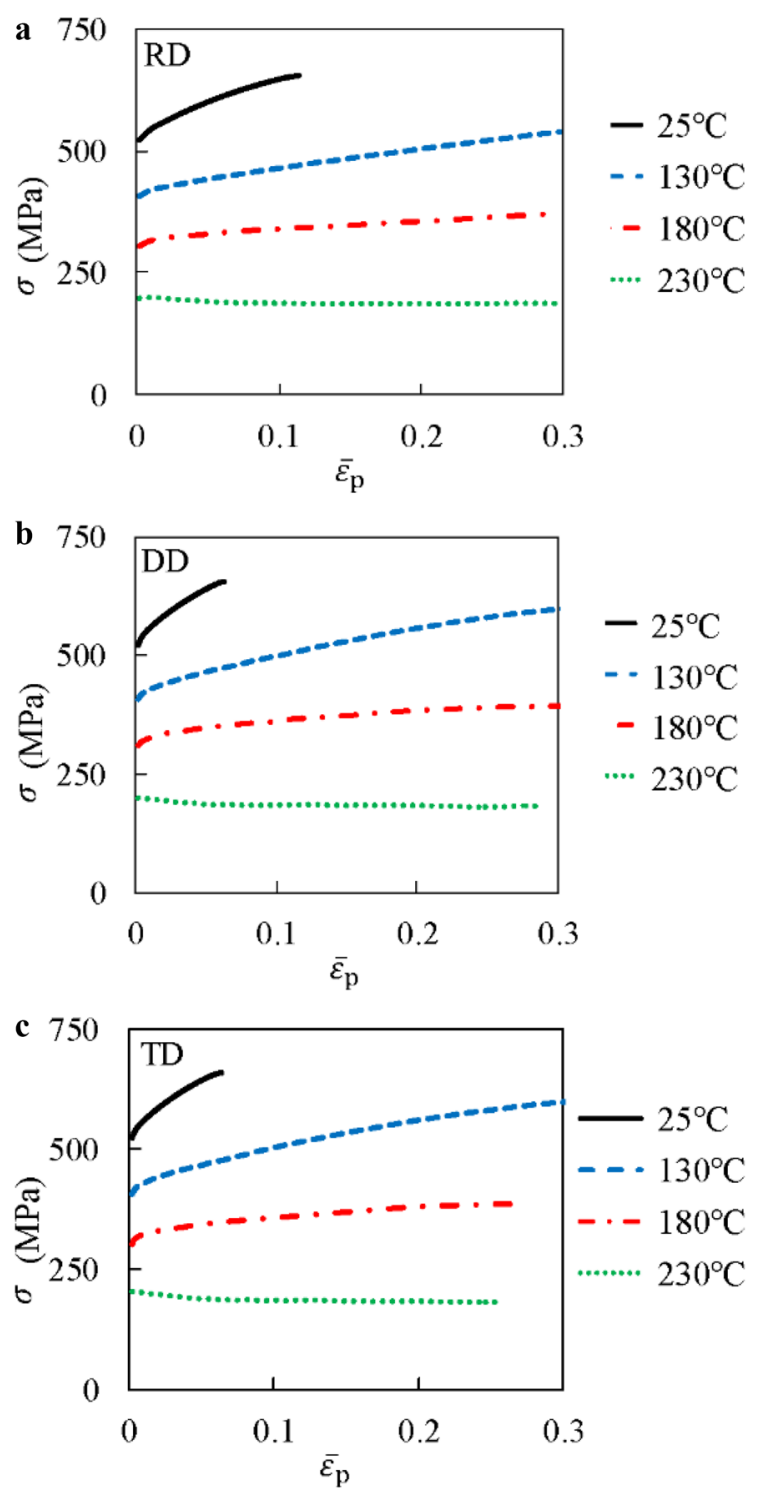

Figure 7 True stress $(\sigma)$ vs. equivalent plastic strain $\left(\bar{\varepsilon}_{\mathrm{p}}\right)$ curves along (a) RD, (b) DD and (c) TD at elevated temperatures

along different directions at the temperatures of $25{ }^{\circ} \mathrm{C}$, $130{ }^{\circ} \mathrm{C}, 180{ }^{\circ} \mathrm{C}$ and $230{ }^{\circ} \mathrm{C}$. The equivalent plastic strain $\left(\bar{\varepsilon}_{\mathrm{p}}\right)$ is defined by Eq. (1) to evaluate plastic deformation and impose plastic work equivalency between various stress states,

$$
\bar{\varepsilon}_{\mathrm{p}}=\int \mathrm{d} \bar{\varepsilon}_{\mathrm{p}}=\int \frac{\dot{w}_{\mathrm{p}}}{\sigma_{0}}=\int \frac{\sigma: \dot{\boldsymbol{\varepsilon}}^{\mathrm{p}}}{\sigma_{0}}=\int \frac{\sigma_{\theta} \mathrm{d} \varepsilon_{\theta}^{\mathrm{p}}}{\sigma_{0}}
$$

where $\sigma_{0}$ is the yield stress under uniaxial tension along the $\mathrm{RD}$, and $\theta$ is the angle between the length direction of specimens and the RD. The initial yield stress decreases with an increase of temperature. Work hardening was 
observed at temperatures from 25 to $180{ }^{\circ} \mathrm{C}$, while $\sigma$ vs. $\bar{\varepsilon}_{\text {p }}$ curves are almost flat at $230^{\circ} \mathrm{C}$ and softening is dominated at this temperature. The softening effect is due to the increasing dislocation mobility caused by dynamic recovery at warm temperatures [25].

\subsection{Experimental Yield Loci}

As shown in Figure 8(a), fracture occurred on the arm of cruciform specimens at $25^{\circ} \mathrm{C}$. The plastic deformation in the gage area of cruciform specimens was limited, and only the initial yield locus (with $\bar{\varepsilon}_{\mathrm{p}}$ of 0.002 ) can be obtained at $25^{\circ} \mathrm{C}$. To enlarge the plastic deformation in the gage region of cruciform, scholars modified the cruciform by reducing thickness of the gage or by strengthening the arms. Liu et al. [26] developed an optimal shape with a flat circular thickness reduction in the gauge region, which permits to reach an experimental biaxial stress vs. strain curve for AA5086 up to 0.30 of equivalent plastic strain. An arm strengthening method via laser deposition using materials compatible with the test material was developed by Hou et al. [27]. This method was verified using various materials to significantly enlarge the obtainable maximum plastic strain in the gage of cruciforms of aluminum alloy AA5754-O [28], dual-phase steels (e.g., DP590, DP780 and DP980) [29] and quenching and partitioning steel QP980 [30, 31].

Fracture occurred at the end of slits close to the central gage area at elevated temperatures, as shown in Figure 8(b), which led to relatively larger plastic deformation. The maximum equivalent plastic strains achieved in the gage area of specimen at the four investigated temperatures and three loading ratios are listed in Table 2. According to the data processing procedure proposed by Min et al. [24], experimental yield loci of AA7075T6 associated with $\bar{\varepsilon}_{\mathrm{p}}=0.002$ are presented in Figure 9 . Note that the data associated with stress ratios $\left(\sigma_{22}: \sigma_{11}\right)$ of 0:1 and 1:0 are from the uniaxial tensile tests of specimens along $\mathrm{RD}$ and $\mathrm{TD}$, respectively. It can be found from Figure 9 that the experimental yield locus at initial yielding decreases with increasing temperature.

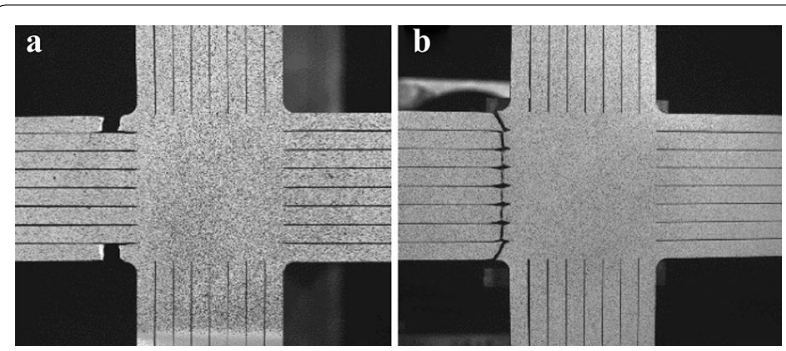

Figure 8 Cruciform pecimens tested at (a) $25^{\circ} \mathrm{C}$ and (b) $230^{\circ} \mathrm{C}$ with a force ratio $\left(F_{x}: F_{y}\right)$ of $2: 1$
Table 2 Maximum equivalent plastic strains achieved in the gage area of cruciform specimens at various temperatures

\begin{tabular}{llll}
\hline Temp. $\left({ }^{\circ} \mathrm{C}\right)$ & $F_{\boldsymbol{x}}: F_{\boldsymbol{y}}=1: 2$ & $F_{\boldsymbol{x}}: F_{\boldsymbol{y}}=1: 1$ & $F_{\boldsymbol{x}}: F_{\boldsymbol{y}}=\mathbf{2 : 1}$ \\
\hline 25 & 0.002 & 0.002 & 0.002 \\
130 & 0.006 & 0.010 & 0.006 \\
180 & 0.008 & 0.020 & 0.008 \\
230 & 0.030 & 0.035 & 0.015 \\
\hline
\end{tabular}

To compare the shape of yield loci at various temperatures as well as their evolving behavior as a function of $\bar{\varepsilon}_{\mathrm{p}}$, the yield loci are normalized by the yield stress $\left(\sigma_{0}\right)$ under uniaxial tension along the RD. Figure 10 presents the normalized yield loci associated with $\bar{\varepsilon}_{\mathrm{p}}=0.002$ and $\bar{\varepsilon}_{\mathrm{p}}=0.01$ at elevated temperatures. It can be found that the shapes of yield loci are almost temperature-independent at both $\bar{\varepsilon}_{\mathrm{p}}=0.002$ and $\bar{\varepsilon}_{\mathrm{p}}=0.01$.

The normalized yield loci associated with different $\bar{\varepsilon}_{\mathrm{p}}$ at 130,180 and $230{ }^{\circ} \mathrm{C}$ are presented in Figure 11 . At the same temperature, it is clear that the yield locus expands with an increase of $\bar{\varepsilon}_{\mathrm{p}}$, especially under the equi-biaxial tension. This is attributed to the fact that the work hardening rate under biaxial tension is higher than that under uniaxial tension, e.g., as shown in Figure 12 when the testing temperature was $180{ }^{\circ} \mathrm{C}$. It is also observed that the evolving characteristics of yield loci is more pronounced at 180 and $230{ }^{\circ} \mathrm{C}$.

\subsection{Modeling the Yield Behavior of AA7075-T6 3.3.1 Evaluation of Constitutive Models}

The von Mises, Hill48, and Yld2000-2d yield criteria are three classical ones and widely used in finite element simulation. A brief introduction to the three yield criteria is provided below.

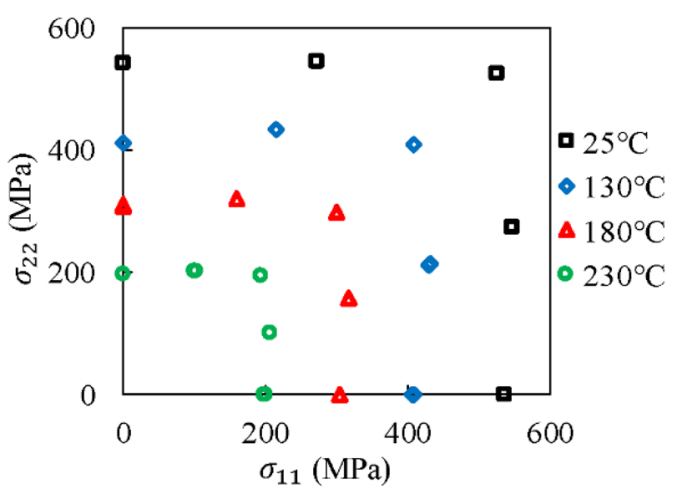

Figure 9 Experimental yield loci with $\bar{\varepsilon}_{\mathrm{p}}=0.002$ at various temperatures 


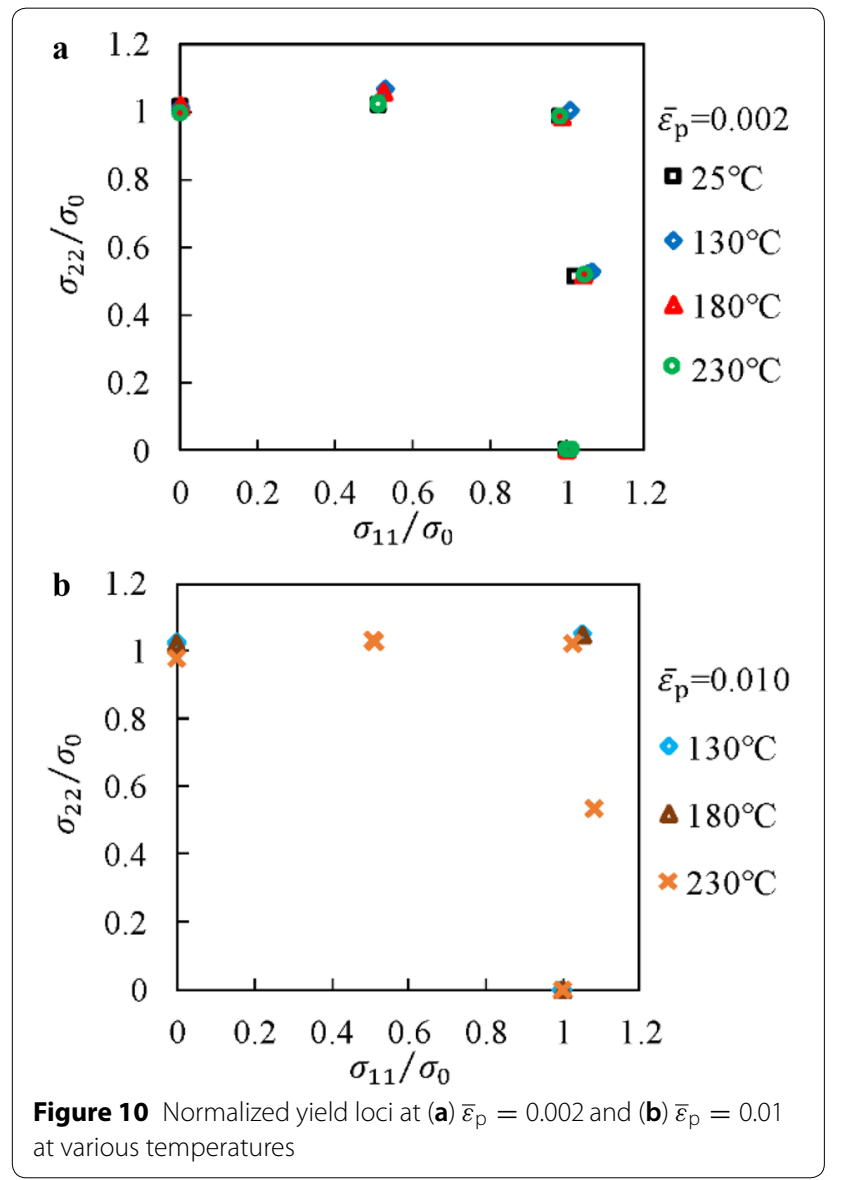

Von Mises yield criterion is isotropic and expressed by:

$$
\bar{\sigma}=\frac{1}{\sqrt{2}} \sqrt{\left(\sigma_{1}-\sigma_{2}\right)^{2}+\left(\sigma_{2}-\sigma_{3}\right)^{2}+\left(\sigma_{3}-\sigma_{1}\right)^{2}}
$$

where $\bar{\sigma}$ is the effective stress.

Under plane stress condition, Hill48 yield criterion [32] which considers in-plane anisotropy can be defined as:

$$
(G+H) \sigma_{11}^{2}-2 H \sigma_{11} \sigma_{22}+(H+F) \sigma_{22}^{2}+2 N \sigma_{12}^{2}=\bar{\sigma}^{2}
$$

where $F, G, H$ and $N$ are four anisotropic parameters, which can be identified from three $r$-values from uniaxial tensile tests using Eq. (4):
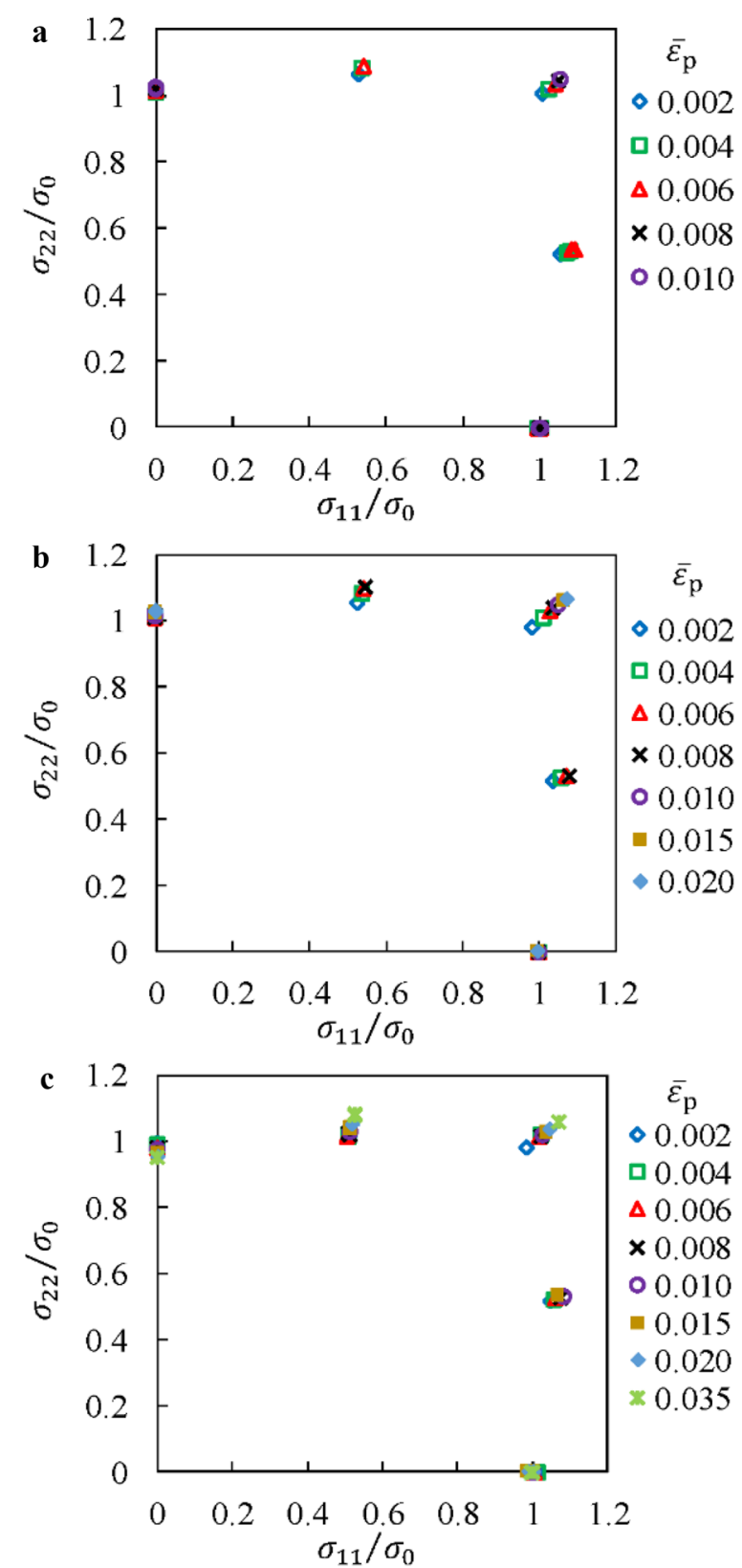

Figure 11 Normalized yield loci at (a) $130{ }^{\circ} \mathrm{C}$, (b) $180^{\circ} \mathrm{C}$ and $(\mathbf{c})$ $230^{\circ} \mathrm{C}$ as a function of equilvalent plastic strain

$$
F=\frac{r_{0}}{r_{90}\left(r_{0}+1\right)}, G=\frac{1}{r_{0}+1}, H=\frac{r_{0}}{r_{0}+1}, N=\frac{\left(r_{0}+r_{90}\right)\left(1+2 r_{45}\right)}{2 r_{90}\left(r_{0}+1\right)} .
$$




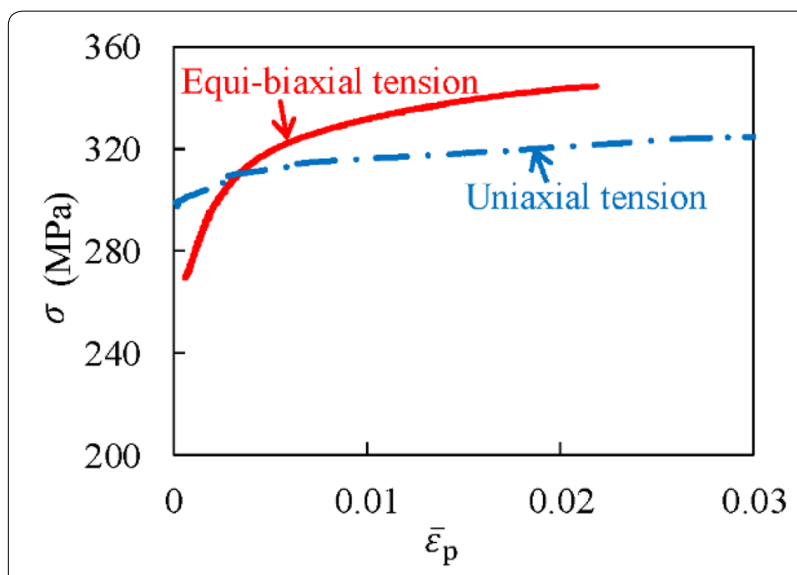

Figure 12 Comparison of $\sigma$ vs. $\bar{\varepsilon}_{\mathrm{p}}$ curves from uniaxial and equi-biaxial tensile testing at $180^{\circ} \mathrm{C}$

Unlike the quadratic von Mises and Hill48 yield criteria, Yld2000-2d yield criterion is non-quadratic and is expressed as [33]

$$
\Phi=\Phi^{\prime}\left(X^{\prime}\right)+\Phi^{\prime \prime}\left(X^{\prime \prime}\right)=2 \bar{\sigma}^{m}
$$

where

$$
\begin{aligned}
& \Phi^{\prime}=\left|X_{1}^{\prime}-X_{2}^{\prime}\right|^{m}, \\
& \Phi^{\prime \prime}=\left|2 X^{\prime \prime}{ }_{2}+X^{\prime \prime}{ }_{1}\right|^{m}+\left|2 X^{\prime \prime}{ }_{1}+X^{\prime \prime}{ }_{2}\right|^{m} .
\end{aligned}
$$

The exponent $m$ is a material coefficient associated with crystal structure and is suggested to be 8 for materials with face centered cubic (FCC), e.g., aluminum alloys. $X_{1}$ and $X_{2}$ are the principal values of matrix $X^{\prime}$ and $X^{\prime \prime}$.

$$
X_{1}=\frac{1}{2}\left(X_{11}+X_{22}+\sqrt{\left(X_{11}-X_{22}\right)^{2}+4 X_{12}^{2}}\right),
$$

$$
X_{2}=\frac{1}{2}\left(X_{11}+X_{22}-\sqrt{\left(X_{11}-X_{22}\right)^{2}+4 X_{12}^{2}}\right) .
$$

Components $X^{\prime}$ and $X^{\prime \prime}$ are obtained from the following linear transformations of the Cauchy stress.

$$
\begin{aligned}
& X^{\prime}=L^{\prime} \cdot \sigma, \\
& X^{\prime \prime}=L^{\prime \prime} \cdot \sigma,
\end{aligned}
$$

where

$$
\left[\begin{array}{l}
L_{11}^{\prime} \\
L_{12}^{\prime} \\
L_{21}^{\prime} \\
L_{22}^{\prime} \\
L_{66}^{\prime}
\end{array}\right]=\left[\begin{array}{llr}
2 / 3 & 0 & 0 \\
-1 / 3 & 0 & 0 \\
0 & -1 / 3 & 0 \\
0 & 2 / 3 & 0 \\
0 & 0 & 1
\end{array}\right]\left[\begin{array}{c}
\alpha_{1} \\
\alpha_{2} \\
\alpha_{7}
\end{array}\right],
$$

$$
\left[\begin{array}{l}
L_{11}^{\prime \prime} \\
L_{12}^{\prime \prime} \\
L_{21}^{\prime \prime} \\
L_{22}^{\prime \prime} \\
L_{66}^{\prime \prime}
\end{array}\right]=\left[\begin{array}{lllll}
-2 & 2 & 8 & -2 & 0 \\
1 & -4 & -4 & 4 & 0 \\
4 & -4 & -4 & 1 & 0 \\
-2 & 8 & 2 & -2 & 0 \\
0 & 0 & 0 & 0 & 1
\end{array}\right]\left[\begin{array}{l}
\alpha_{3} \\
\alpha_{4} \\
\alpha_{5} \\
\alpha_{6} \\
\alpha_{8}
\end{array}\right]
$$

In Eqs. (8)-(9), $\sigma$ is Cauchy stress and the material parameters $\alpha_{1}-\alpha_{8}$ are eight anisotropy coefficients calibrated from $\sigma_{0}, \sigma_{45}, \sigma_{90}, r_{0}, r_{45}, r_{90}, \sigma_{\mathrm{b}}$ and $r_{\mathrm{b}}$, where $\sigma_{\theta}$ and $r_{\theta}$ are the uniaxial yield stress and $r$-value (Lankford coefficient) measured along the direction having an angle of $\theta$ to the RD, respectively, and $\sigma_{\mathrm{b}}$ and $r_{\mathrm{b}}$ are the equi-biaxial yield stress and the ratio of plastic strain rate under equi-biaxial tension, respectively [34].

The yield stresses and $r$-values of AA7075-T6 with $\bar{\varepsilon}_{\mathrm{p}}=0.002$ at various temperatures are summarized in Table 3. It is found that $r_{90}$ decreases as the temperature increases from 180 to $230^{\circ} \mathrm{C}$. In addition, the $r$-value obtained from uniaxial tension remains nearly constant

Table 3 Flow stresses and $r$-values of AA7075-T6 with $\bar{\varepsilon}_{\mathrm{p}}=\mathbf{0 . 0 0 2}$

\begin{tabular}{lllllllll}
\hline $\begin{array}{l}\text { Temp. } \\
\left({ }^{\circ} \mathbf{C}\right)\end{array}$ & $\sigma_{0}$ & $\sigma_{\mathbf{4 5}}$ & $\sigma_{\mathbf{9 0}}$ & $\sigma_{\mathbf{b}}$ & $\boldsymbol{r}_{\mathbf{0}}$ & $\boldsymbol{r}_{\mathbf{4 5}}$ & $\boldsymbol{r}_{\mathbf{9 0}}$ & $\boldsymbol{r}_{\mathbf{b}}$ \\
\hline 25 & 536 & 540 & 542 & 527 & 0.63 & 0.81 & 1.1 & 0.89 \\
130 & 408 & 407 & 413 & 410 & 0.63 & 0.8 & 1.11 & 0.71 \\
180 & 305 & 313 & 309 & 300 & 0.65 & 0.84 & 1.07 & 0.67 \\
230 & 198 & 198 & 197 & 194 & 0.67 & 0.81 & 0.85 & 0.58 \\
\hline
\end{tabular}


despite the temperature variation and $r_{\mathrm{b}}$ decreases with increasing temperature gradually. The fitted parameters of the Hill48 yield function in Eq. (3) and the Yld2000$2 d$ yield function in Eq. (9) are summarized in Tables 4 and 5 , respectively.

The yield loci calculated by the von Mises, Hill48 and Yld2000-2d yield criteria are presented in Figure 13. Compared with the other two yield functions, Yld2000$2 \mathrm{~d}$ gives prediction in better agreement with the experimental data.

Figure 14 shows the predicted uniaxial yield stresses and $r$-values along various angles to the RD using three yield functions, and these predictions are compared with the experimental results at $130{ }^{\circ} \mathrm{C}$. Uniaxial stresses predicted by the Hill 48 criterion are larger than the experimental stresses, and the von Mises and Yld2000-2d yield functions give accurate prediction of uniaxial yield stresses, as shown in Figure 12(a). In Figure 12(b), large deviations between $r$-values predicted by von Mises and experimental results are observed. The Hill48 and Yld2000-2d yield criteria give nearly the same prediction in $r$-value along different angles to the RD, and the results are in good agreement with

Table 4 Identified parameters in the Hill48 yield function

\begin{tabular}{lllll}
\hline $\begin{array}{l}\text { Temp. } \\
\left({ }^{\circ} \mathbf{C}\right)\end{array}$ & $\boldsymbol{F}$ & $\boldsymbol{G}$ & $\boldsymbol{H}$ & $\boldsymbol{N}$ \\
\hline 25 & 0.3491 & 0.6146 & 0.3854 & 1.2644 \\
130 & 0.3492 & 0.6131 & 0.3869 & 1.2481 \\
180 & 0.3678 & 0.6064 & 0.3936 & 1.3045 \\
230 & 0.4639 & 0.6039 & 0.3961 & 1.403 \\
\hline
\end{tabular}

experimental data. In summary, the Yld2000-2d criterion, namely, the non-quadratic anisotropic yield equation, provides the most accurate prediction in the yield behavior of AA7075-T6 at elevated temperatures, among the three investigated yield criteria.

\subsubsection{Influence of the Exponent Value in the YId2000-2d Criterion on Calculated Yield Loci}

In order to investigate the influence of the exponent $m$ in the Yld2000-2d criterion on the predicted yield surface, initial yield loci from Yld000-2d with exponent varying from 6 to 26 are shown in Figure 15. It can be observed from Figure 15 that the exponent has a significant impact on the curvature of the predicted yield surface. As the exponent $m$ increases, the curve between the uniaxial tension and equi-biaxial tends to be straight. To evaluate the errors when applying different exponent values to predicting yield loci, the root mean square error (RMSE) is used,

$$
\text { RMSE }=\sqrt{\frac{1}{N} \sum_{i}^{N}\left(\frac{\sigma_{\mathrm{f}}}{\sigma_{\mathrm{e}}}-1\right)^{2}},
$$

where $\sigma_{\mathrm{e}}$ is the experimental value, $\sigma_{\mathrm{f}}$ is the predicted value, and $N$ is the number of experimental data sets (or stress ratios), which is 5 in this work. Figure 16 shows the calculated RMSEs by the Yld2000-2d criterion with different $m$ values at various temperatures. At $25^{\circ} \mathrm{C}$, the RMSE decreases as $m$ increases. At other temperatures, the RMSE decreases at first and then increases with an increase of $m$ value. The averaged RMSE is indicated by the solid line in Figure 16. It can be seen that the averaged RMSE decreases as $m$ increases from 6 to 14, and increases slightly as $m$ increases from 14 to 26 . Therefore,

Table 5 Identified parameters in the YId2000-2d yield function with an exponent of 8

\begin{tabular}{|c|c|c|c|c|c|c|c|c|c|}
\hline $\begin{array}{l}\text { Temp. } \\
\left({ }^{\circ} \mathrm{C}\right)\end{array}$ & $\alpha_{1}$ & $\alpha_{2}$ & $\alpha_{3}$ & $\alpha_{4}$ & $\alpha_{5}$ & $\alpha_{6}$ & $\alpha_{7}$ & $\alpha_{8}$ & $m$ \\
\hline 25 & 0.9129 & 1.0522 & 1.0654 & 0.9937 & 1.0241 & 1.0014 & 0.981 & 0.989 & 8 \\
\hline 130 & 0.9212 & 1.0378 & 0.974 & 0.9755 & 1.022 & 0.9943 & 0.9835 & 1.044 & \\
\hline 180 & 0.9457 & 1.0201 & 0.9957 & 0.9827 & 1.0329 & 1.0581 & 0.9681 & 0.9463 & \\
\hline 230 & 0.9688 & 0.997 & 0.9118 & 0.9934 & 1.0395 & 1.1013 & 0.9871 & 1.0094 & \\
\hline
\end{tabular}



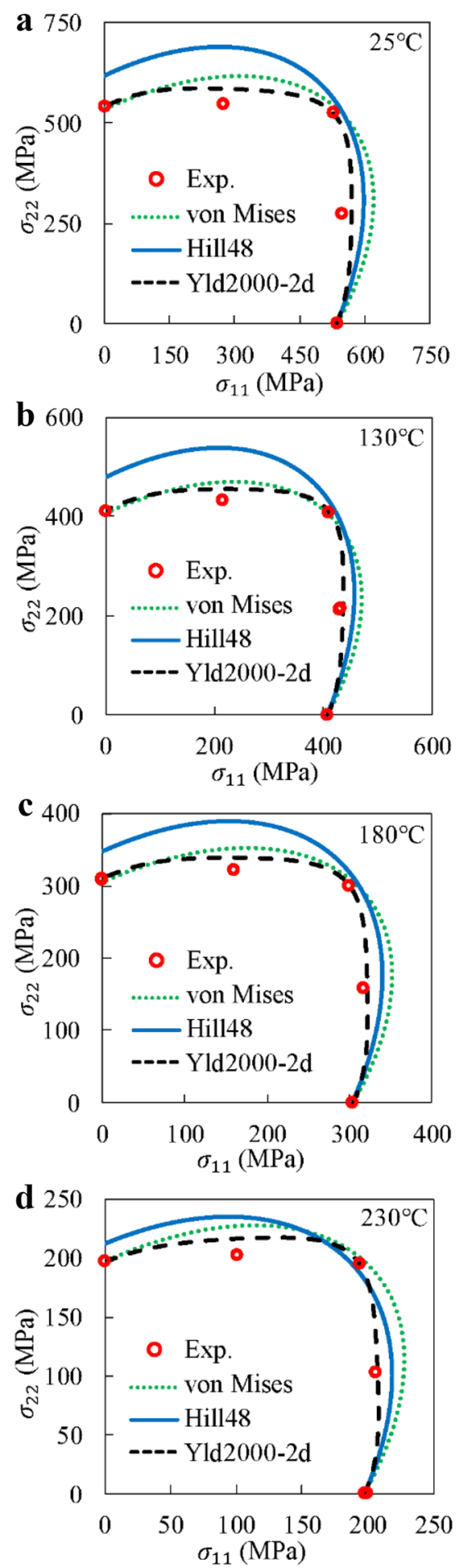

Figure 13 Comparision of yield loci from experiments and calcalated by yield functions wih $\bar{\varepsilon}_{\mathrm{p}}=0.002$ at $(\mathbf{a}) 25^{\circ} \mathrm{C},(\mathbf{b}) 130^{\circ} \mathrm{C},(\mathbf{c})$ $180^{\circ} \mathrm{C}$ and $(\mathbf{d}) 230^{\circ} \mathrm{C}$
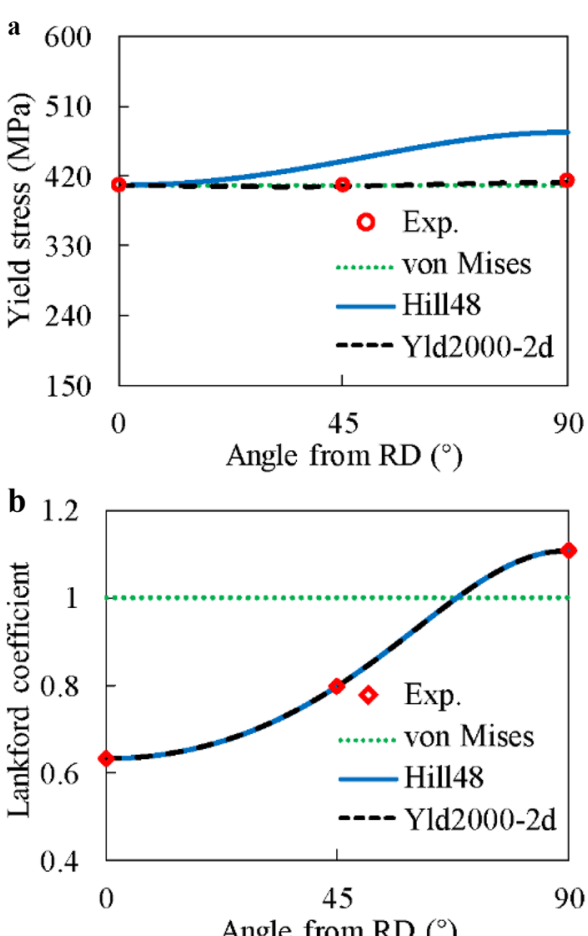

Figure 14 Comparison of calculated and experimental (a) uniaxial yield stresses and (b) $r$-values at various angles to the RD at $130^{\circ} \mathrm{C}$

the Yld2000-2d yield function with $m=14$ gives the lowest RMSE when predicting yield loci of AA7075-T6. The experimental yield loci associated with $\bar{\varepsilon}_{\mathrm{p}}=0.01$ are compared with the calculated ones by the Yld2000$2 \mathrm{~d}$ yield criterion with $m=14$ in Figure 17. Results show that the predicted yield loci are in good agreement with experimental data points, which indicates that the Yld2000-2d yield criterion with $m=14$ accurately predicts yield loci of AA7075-T6 at elevated temperature not only at the initial yielding but also during the subsequent yielding. The identified parameters of the Yld2000-2d yield function with $m=14$ when $\bar{\varepsilon}_{\mathrm{p}}$ is equal to 0.002 and 0.01 are listed in Tables 6 and 7 , respectively.

\section{Conclusions}

In this study, the yield loci of AA7075-T6 at elevated temperatures from 25 to $230{ }^{\circ} \mathrm{C}$ were obtained through uniaxial and biaxial tensile testing with the aids of induction heating and DIC techniques, and the yield behavior at various temperatures have been investigated. The following conclusions can be drawn. 

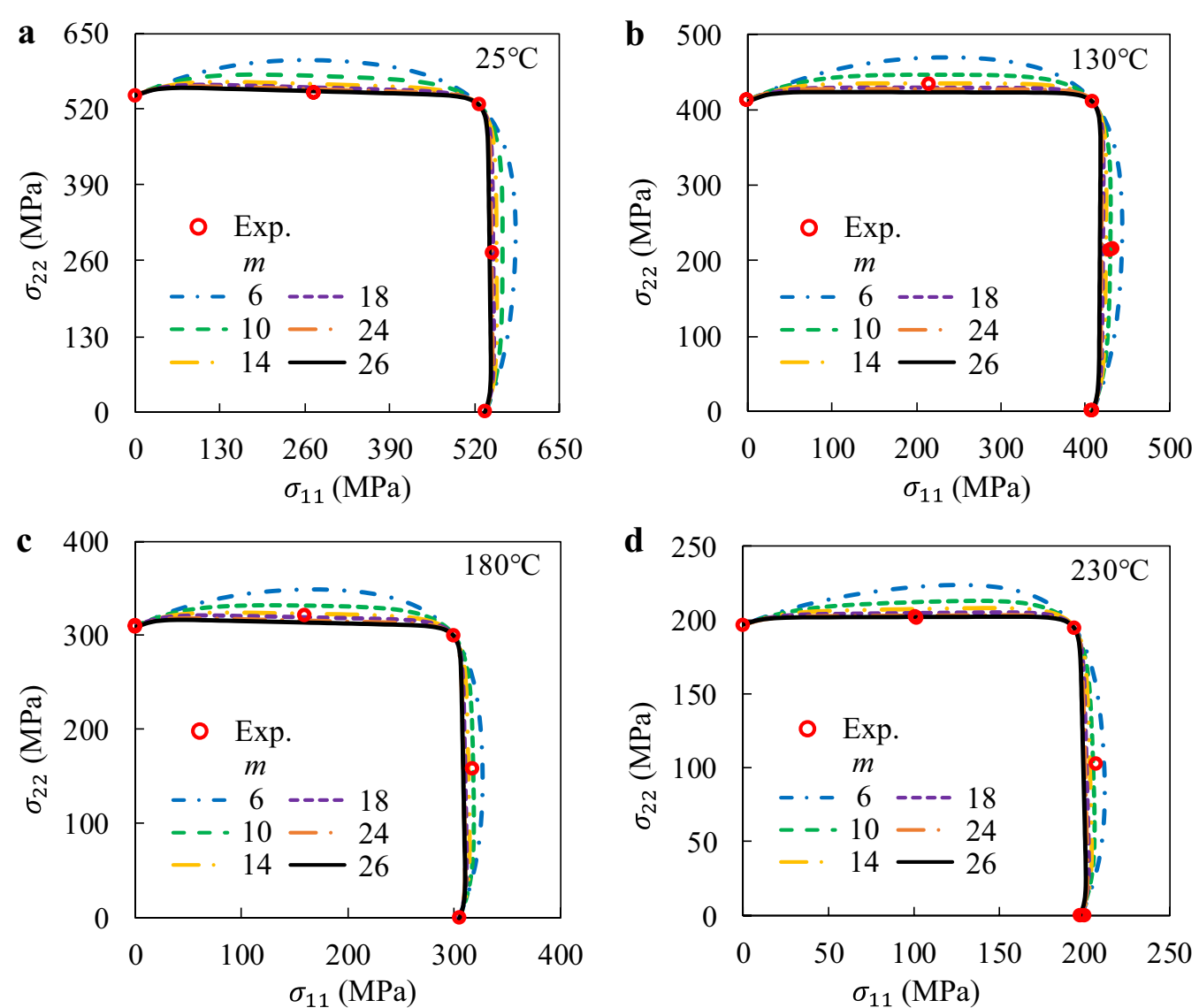

Figure 15 Initial yield loci from Yld2000-2d yield criterion with different exponent factors at (a) $25^{\circ} \mathrm{C}$, (b) $130{ }^{\circ} \mathrm{C}$, (c) $180^{\circ} \mathrm{C}$ and (d) $230{ }^{\circ} \mathrm{C}$

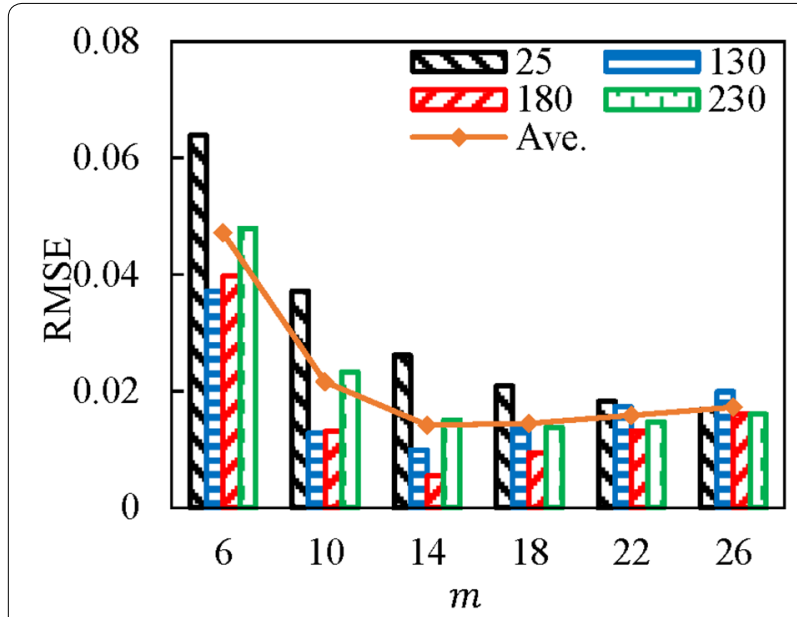

Figure 16 RMSEs calculated by Yld2000-2d criterion with different exponent factors at $25^{\circ} \mathrm{C}, 130^{\circ} \mathrm{C}, 180^{\circ} \mathrm{C}$ and $230^{\circ} \mathrm{C}$

(1) The von Mises, Hill48 and Yld2000-2d yield functions are calibrated using uniaxial yield stresses and $r$-values at $0^{\circ}, 45^{\circ}, 90^{\circ}$ to the $\mathrm{RD}$, the equi-biaxial

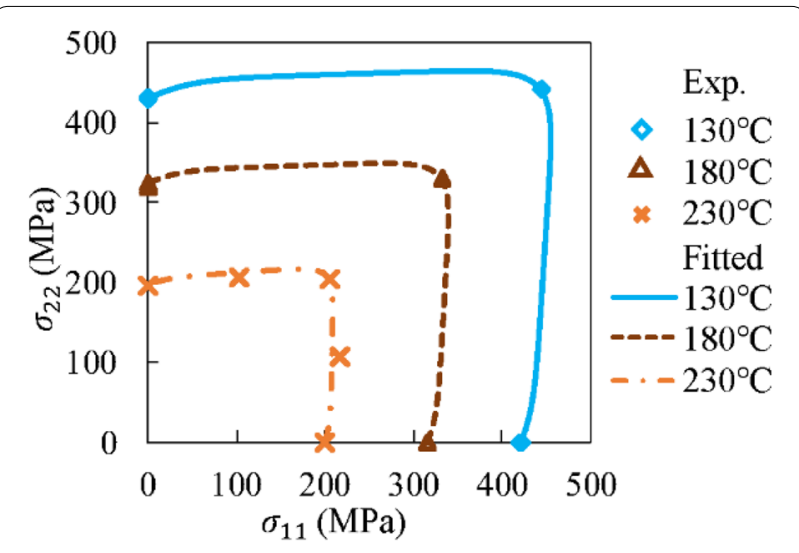

Figure 17 Yld2000-2d theoretical yield loci with exponent factor of $14\left(\bar{\varepsilon}_{p}=0.01\right)$

yield stress and the plastic strain ratio under equibiaxial tension at various temperatures.

(2) Through comparison of experimental results with three yield functions, Yld2000-2d yield function, 
Table 6 Identified parameters of YId2000-2d yield function with $m=14\left(\bar{\varepsilon}_{p}=0.002\right)$

\begin{tabular}{llllllllll}
\hline $\begin{array}{l}\text { Temp. } \\
\left({ }^{\circ} \mathrm{C}\right)\end{array}$ & $\boldsymbol{\alpha}_{\mathbf{1}}$ & $\boldsymbol{\alpha}_{\mathbf{2}}$ & $\boldsymbol{\alpha}_{\mathbf{3}}$ & $\boldsymbol{\alpha}_{\mathbf{4}}$ & $\boldsymbol{\alpha}_{\mathbf{5}}$ & $\boldsymbol{\alpha}_{\mathbf{6}}$ & $\boldsymbol{\alpha}_{\mathbf{7}}$ & $\boldsymbol{\alpha}_{\mathbf{8}}$ & $\boldsymbol{m}$ \\
\hline 25 & 0.9666 & 1.0098 & 1.0479 & 0.9984 & 1.0172 & 1.0233 & 0.9864 & 0.9795 \\
130 & 0.9673 & 1.0048 & 0.9825 & 0.983 & 1.0108 & 0.9954 & 0.9924 & 1.0284 \\
180 & 0.9778 & 0.9976 & 1.0174 & 0.9915 & 1.0216 & 1.0476 & 0.9711 & 0.9399 \\
230 & 0.9737 & 1.0111 & 0.9759 & 1.0022 & 1.0262 & 1.0698 & 0.9933 & 0.995 \\
\hline
\end{tabular}

Table 7 Identified parameters of YId2000-2d yield function withm $=14\left(\bar{\varepsilon}_{\mathrm{p}}=0.01\right)$

\begin{tabular}{lllllllll}
\hline $\begin{array}{l}\text { Temp. } \\
\left({ }^{\circ} \mathrm{C}\right)\end{array}$ & $\boldsymbol{\alpha}_{\mathbf{1}}$ & $\boldsymbol{\alpha}_{\mathbf{2}}$ & $\boldsymbol{\alpha}_{\mathbf{3}}$ & $\boldsymbol{\alpha}_{\mathbf{4}}$ & $\boldsymbol{\boldsymbol { \alpha } _ { \mathbf { 5 } }}$ & $\boldsymbol{\alpha}_{\mathbf{6}}$ & $\boldsymbol{\alpha}_{\mathbf{7}}$ & \\
\hline 130 & 0.9701 & 0.9823 & 0.9063 & 0.9581 & 0.989 & 0.8982 & 0.969 \\
180 & 0.9783 & 0.9733 & 0.904 & 0.9577 & 0.99 & 0.9063 & 0.9581 \\
230 & 0.9505 & 1.0397 & 0.8822 & 0.9928 & 1.0073 & 0.9819 & 1.0029 \\
\hline
\end{tabular}

namely, the non-quadratic anisotropic yield equation, is verified to give a better prediction to the yield loci of AA7075-T6 within the investigated temperature range.

(3) An exponent of 14 in the Yld2000-2d yield function is for the yield loci of AA7075-T6 at elevated temperatures.

(4) Hardening of AA7075-T6 at elevated temperatures is found stress-state-dependent.

\section{Acknowledgements}

Not applicable.

\section{Authors' contributions}

$J L$ and $J M$ conceived and designed the study; XB performed the experiments and wrote the initial manuscript; $Y H$ assisted with the results analysis; $X Q, Z T$ and $\mathrm{JC}$ reviewed and edited the manuscript. All authors read and approved the final manuscript.

\section{Authors' Information}

Jianping Lin, born in 1958, is currently a full professor at the School of Mechanical Engineering, Tongji University, China. His main research interests include automobile lightweight and advanced sheet forming technology.

Xingyu Bao, born in 1995, is currently a master candidate at the School of Mechanical Engineering, Tongji University, China. She received her bachelor degree from Shandong University, China, in 2017. Her research interest is sheet metal forming.

Yong Hou, born in 1993, is currently a PhD candidate at the School of Mechanical Engineering, Tongji University, China. His research interest is sheet metal forming.

Junying Min, born in 1986, is currently a full professor at the School of Mechanical Engineering, Tongji University, China. His main research interests include automobile lightweight and advanced sheet forming technology.

Xinlei Qu, born in 1983, is currently an engineer at Shandong Nanshan Aluminum Co., Ltd, China. He received his bachelor degree on electrical automation from Jinan University, China, in 2007.
Zhimin Tao, born in 1977, is currently an engineer at Shandong Nanshan Aluminum Co., Ltd, China. He received his bachelor degree on mechanical metal working from Northeastern University, China, in 2000.

Jiajie Chen, born in 1988, is currently an engineer at Pan Asia Technical Automotive Center, China. He received his master degree on materials science and engineering from Swiss federal Institute of Technology in Lausa, Switzerland, in 2013

Funding

Supported by National Natural Science Foundation of China (Grant No. 51805375).

Competing interests

The authors declare no competing financial interests.

\section{Author Details}

${ }^{1}$ School of Mechanical Engineering, Tongji University, Shanghai 201804, China

2 Shandong Nanshan Aluminum Co., Ltd, Shandong 265706, China. ${ }^{3}$ Pan Asia

Technical Automotive Center, Shanghai 202106, China.

Received: 19 May 2020 Revised: 9 October 2020 Accepted: 14 October 2020

Published online: 02 November 2020

\section{References}

[1] Jean-Hubert Schmitt,Thierry lung. New developments of advanced highstrength steels for automotive applications. Comptes Rendus Physique, 2018, 19(8): 641-656.

[2] W S Miller, L Zhuang, J Bottema, et al. Recent development in aluminium alloys for the automotive industry. Materials Science and Engineering $A$, 2000, 280(1): 37-49

[3] Yumi Choi, Jinwoo Lee, Sudhy S Panicker, et al. Mechanical properties, springback, and formability of W-temper and peak aged 7075 aluminum alloy sheets: Experiments and modeling. International Journal of Mechanical Sciences, 2019, 170: 105344.

[4] Jinwoo Lee, Hyuk Jong Bong, Daeyong Kim, et al. Application of combined W-temper and cold forming technology to high-strength aluminum alloy automotive parts. JOM, 2019, 71(12): 4393-4404.

[5] Jinwoo Lee, Hyuk Jong Bong, Daeyong Kim, et al. Mechanical properties and formability of heat-treated 7000-series high-strength 
aluminum alloy: Experiments and finite element modeling. Metals \& Materials International, 2020, 26: 682-694.

[6] Hui Wang, Yingbing Luo, Peter Friedman, et al. Warm forming behavior of high strength aluminum alloy AA7075. Transactions of the Nonferrous Metals Society of China, 2012, 22(1): 1-7.

[7] Sławomir Polak, Paweł Kaczyński, Zbigniew Gronostajski, et al. Warm forming of 7075 aluminum alloys. Procedia Engineering, 2017, 207 2399-2404

[8] Johannes A Österreicher, Matheus A Tunes, Florian Grabner, et al. Warm-forming of pre-aged Al-Zn-Mg-Cu alloy sheet. Materials \& Design, 2020, 193: 108837.

[9] Hui Wang, Dawei Yan, Yangmin Liang, et al. Numerical simulation of warm forming behavior of high strength aluminum alloy 7075. Transactions of Nanjing University of Aeronautics and Astronautics, 2016, 33(5): 106-111.

[10] D Raja Satish, Fitsum Feyissa, D Ravi Kumar. Cryorolling and warm forming of AA6061 aluminum alloy sheets. Materials \& Manufacturing Processes, 2017, 32(12): 1345-1352.

[11] S Dicecco, M Di Ciano, C Butcher, et al. Numerical and experimental investigation of the formability of AA6013-T6. Journal of Physics: Conference Series, 2017, 896: 012114.

[12] Nikolay Sotirov, Peter Simon, Christian Chimani, et al. Warm deep drawability of peak-aged 7075 aluminium sheet alloy. Key Engineering Materials, 2012, 504: 955-960.

[13] Torsten Grohmann. Forming of AMAG 7xxx series aluminium sheet alloys. Proceedings of the New Developments in Sheet Metal Forming and New Developments in Hydroforming, Fellbach, Germany, 2016: 10-11.

[14] Yong Hou, Junying Min, Jianping Lin, et al. Springback prediction of sheet metals using improved material models. Procedia Engineering, 2017, 207: 173-178.

[15] Fusahito Yoshida, Takeshi Uemori. A model of large-strain cyclic plasticity describing the Bauschinger effect and workhardening stagnation. International Journal of Plasticity, 2002, 18(5-6): 661-686.

[16] Jianping Lin, Yong Hou, Junying Min, et al. Effect of constitutive model on springback prediction of MP980 and AA6022-T4. International Journal of Material Forming, 2020, 13: 1-13.

[17] Johan Pilthammar, Dorel Banabic, Mats Sigvant. BBC05 with non-integer exponent and ambiguities in Nakajima yield surface calibration. International Journal of Material Forming, 2020: 1-16.

[18] Guowei Zhou, Dayong Li, Yinghong Peng. Investigation of Tensile Deformation Behavior of 7075-T6 at Elevated Temperatures. Applied Mechanics and Materials, 2012, 152:358-363.

[19] Patrick Terriault, Karim Settouane, Vladimir Brailovski. Biaxial testing at different temperatures of cruciform Ti-Ni samples. SMST 2003: Proceedings of the International Conference on Shape Memory and Superelastic Technologies, CA, USA, May 5-8, 2003: 247-257.

[20] H Hamasaki, F Tamashiro. Biaxial deformation on AA5182-O aluminium alloy sheet at warm temperature. Journal of Physics: Conference Series, 2018, 1063(1): 012032
[21] The American Association State Highway and Transportation Officials Standard. ASTM E8/E8M-13A. Standard test methods for tension testing of metallic materials, 2013.

[22] Yasuhiro Hanabusa, Hideo Takizawa, Toshihiko Kuwabara. Numerical verification of a biaxial tensile test method using a cruciform specimen. Journal of Materials Processing Technology, 2013, 213(6): 961-970.

[23] The International Organization for Standardization, ISO 16842:2014(E). Metallic materials - sheet and strip - biaxial tensile testing method using a cruciform test piece.

[24] Junying Min, John E Carsley, Jianping Lin, et al. A non-quadratic constitutive model under non-associated flow rule of sheet metals with anisotropic hardening: modeling and experimental validation. International Journal of Mechanical Sciences, 2016, 119: 343-359.

[25] H P Stüwe. Experimental aspects of crystal plasticity. large plastic deformation of crystalline aggregates. Vienna: Springer, 1997.

[26] Wei Liu, Dominique Guines, Lionel Leotoing, et al. Identification of sheet metal hardening for large strains with an in-plane biaxial tensile test and a dedicated cross specimen. International Journal of Mechanical Sciences, 2015, 101: 387-398

[27] Yong Hou, Junying Min, Jianping Lin, et al. Cruciform specimen design for large plastic strain during biaxial tensile testing. Journal of Physics: Conference Series, 2018: 1063.

[28] Yong Hou, Junying Min, Jianping Lin, et al. Plastic instabilities in AA5754O under various stress states. IOP Conference Series: Materials Science and Engineering, 2018, 418(1): 1-8.

[29] Yong Hou, Junying Min, Nan Guo, et al. Investigation of evolving yield surfaces of dual-phase steels. Journal of Materials Processing Technology, 2019: 116314

[30] Nan Guo, Junying Min, Yong Hou, et al. An experimental study of yield surface evolution of a TRIP-assisted steel. Proceedings of the 13th International Conference on Numerical Methods in Industrial Forming Processes, 2019, NUMIFORM, Portsmouth USA.

[31] Yong Hou, Junying Min, Thomas B Stoughton, et al. A non-quadratic pressure-sensitive constitutive model under non-associated flow rule with anisotropic hardening: Modeling and validation. International Journal of Plasticity, 2020, 135: 102808.

[32] R Hill. A user-friendly theory of orthotropic plasticity in sheet metals. International Journal of Mechanical Sciences, 1993, 35(1): 19-25.

[33] F Barlat, J C Brem, JW Yoon, et al. Plane stress yield function for aluminum alloy sheets - Part 1: Theory. International Journal of Plasticity, 2003, 19(9): 1297-1319

[34] Toshihiko Kuwabara, Takahiro Mori, Mineo Asano, et al. Material modeling of 6016-O and 6016-T4 aluminum alloy sheets and application to hole expansion forming simulation. International Journal of Plasticity, 2017, 93: 164-186.

\section{Submit your manuscript to a SpringerOpen ${ }^{\circ}$ journal and benefit from:}

- Convenient online submission

- Rigorous peer review

- Open access: articles freely available online

- High visibility within the field

- Retaining the copyright to your article

Submit your next manuscript at $\boldsymbol{\nabla}$ springeropen.com 